\title{
BMJ Factors influencing the inclusion of Open complementary and alternative medicine (CAM) in undergraduate medical education
}

\author{
Kevin R Smith
}

To cite: Smith KR. Factors influencing the inclusion of complementary and alternative medicine (CAM) in undergraduate medical education. BMJ Open 2011;1: e000074. doi:10.1136/ bmjopen-2011-000074

- Prepublication history for this paper is available online. Additional appendices are published online only. To view these files please visit the journal online (http:// bmjopen.bmj.com).

Received 27 January 2011 Accepted 9 May 2011

This final article is available for use under the terms of the Creative Commons Attribution Non-Commercial 2.0 Licence; see http://bmjopen.bmj.com
School of Contemporary Sciences, Abertay University, Dundee, UK

\section{Correspondence to} Dr Kevin R Smith; k.smith@tay.ac.uk

\section{ABSTRACT}

Objective: To investigate the views and practices of UK medical schools regarding the inclusion (or exclusion) of complementary and alternative medicine (CAM) in undergraduate medical curricula.

Design: Survey (by email) of UK medical schools offering MBBS (or equivalent) degrees.

Results: The overall response rate was $58.1 \%$ (18/31). All respondents indicated that their curricula included CAM elements. However, the quantity of CAM within curricula varied widely between medical schools, as did the methods by which CAM education was delivered. General Medical Council requirements were the strongest factor influencing the inclusion of CAM, although medical student preferences were also important. Respondents were generally satisfied with the extent of CAM provision within their curricula, while a wide range of views on the appropriateness of CAM in the medical curriculum were held by faculty members.

Conclusions: It may be useful for the General Medical Council to clarify the extent to which CAM should be incorporated into the curriculum. Current CAM education appears to exist primarily as a means of educating future doctors on the modalities that their patients may use or request. However, some forms of pedagogy arguably risk students assimilating CAM advocacy in an uncritical fashion.

\section{INTRODUCTION}

This paper examines the inclusion (or otherwise) of complementary and alternative medicine (CAM) in medical syllabi in UK medical schools.

Various definitions of CAM exist. For example, the WHO defines CAM as "a broad set of health care practices that are not part of that country's own tradition and are not integrated into the dominant health care system". ${ }^{1}$ Another example is the definition used by the US National Center for Complementary and Alternative Medicine: "a group of diverse medical and health care systems, practices, and products, that are not currently part of

\section{ARTICLE SUMMARY}

\section{Article focus}

- To investigate the views and practices of UK medical schools regarding the inclusion (or exclusion) of complementary and alternative medicine (CAM) in undergraduate medical curricula.

Key messages

n The General Medical Council is urged to clarify the extent to which CAM should be incorporated into the curriculum.

- Current CAM education appears to exist primarily as a means of educating future doctors on the modalities that their patients may use or request.

- A wide range of approaches to, and views on, the teaching of CAM were found.

Strengths and limitations of this study

- All UK medical schools were surveyed.

- Deans (or equivalent) were the subjects of the survey.

- A $58.1 \%$ response rate was attained, which was reasonable but ideally should have been higher to permit generalisation of the findings.

- The different types of CAM were not explored.

- Some of the survey questions could have been better phrased.

- Teaching and learning approaches should be examined further.

conventional medicine". ${ }^{2}$ It is worth noting that some opponents of CAM have objected to the term 'complementary and alternative medicine', claiming that such usage originated as a form of language distortion by CAM advocates. $^{3}{ }^{4}$ The difficulties of defining CAM are perhaps best summarised by a House of Lords report which stated: "The CAM community has been struggling for fifteen years to come up with a single definition of CAM agreed by all, but with no success" ${ }^{5}$

Of particular relevance to this paper are definitions employed by relevant UK sources. For example, NHS Evidence provides the following statement: 
The term 'alternative medicine' was originally introduced to refer to whole medical systems that did not fit with conventional medicine. These systems have completely different philosophies together with different ideas on causes of disease, methods of diagnosis and approaches to treatment and were seen as a replacement for conventional healthcare. 'Complementary medicine' (or 'therapies') is used to refer to those methods which can be used alongside or to 'complement' conventional medicine, but the distinction between alternative and complementary medicine is not absolute and may depend on the context. Many people now use the term 'complementary and alternative medicine (CAM)' to include both approaches. ${ }^{6}$

However, several major UK bodies do not offer their own definitions of CAM. These bodies include the Department of Health, the General Medical Council (GMC) and the National Institute for Health and Clinical Excellence (NICE).

Given the foregoing difficulties in defining CAM, it is perhaps more effective to list the forms of CAM actually used by patients, rather than attempt to claim a precise definition of CAM. In the UK, the major forms of CAM used by patients have been reported to include (in order of frequency of use) herbal medicine, aromatherapy, homeopathy, acupuncture/acupressure, massage, reflexology, osteopathy and chiropractic. ${ }^{7}$

CAM encompasses a set of therapeutic modalities which occupy a paradoxical position in modern medicine and healthcare: the plausibility and evidence base of many CAM treatments is very limited, and CAM approaches have been criticised and challenged by some scientists and physicians opposed to CAM; despite this, some forms of CAM are manifestly popular among many lay people and a significant number of medical professionals. $^{8-10}$

Such increased demand has reached the sphere of education. Indeed several universities in the UK, USA and elsewhere have in recent years launched degree-level education and training in CAM. ${ }^{11-16}$ Perhaps most importantly, undergraduate medical education (ie, the means by which future medical doctors are produced) is also showing signs of being influenced by the increased prominence of CAM. The GMC sets the standards for undergraduate medical syllabi in the UK, via its document Tomorrow's Doctors-Outcomes and Standards for Undergraduate Medical Education. The most recent (2009) version of this document (due for application from 2011/12 onwards) requires, as an educational outcome, that graduate doctors must: "Demonstrate awareness that many patients use complementary and alternative therapies, and awareness of the existence and range of these therapies, why patients use them, and how this might affect other types of treatment that patients are receiving". ${ }^{17}$ This outcome is open to fairly wide interpretation.

Individual medical schools must satisfy the requirements of the GMC, but are not limited by these requirements. Thus, although the above outcome from
Tomorrow's Doctors appears only to demand the inculcation of a simple 'awareness' of CAM, a medical school could choose to deliver as much CAM education as it wished, insofar as time existed in the syllabus for its inclusion. In this regard, other pressures (beyond GMC requirements) may operate to promote-or limit-the adoption of CAM into medical syllabi.

A wide variety of factors influencing patient and physician attitudes to CAM have been reported in a number of studies. ${ }^{18-26}$ Such factors may be expected to translate into influences on the content of medical syllabi. In this respect, possible factors include personal viewpoints about CAM among the academics charged with syllabus design, knowledge of research evidence, contact with other health professionals, patient feedback, societal pressures, personal experience, funding pressures and student feedback.

Decisions to include/exclude syllabus elements are not made in an ethical vacuum, and there exist, in common with many components of contemporary medical education, ethical concerns surrounding the question of CAM inclusion/exclusion from syllabi. ${ }^{18}{ }^{27-31}$ For example, CAM may find ethical favour among some because it is claimed to be an expression of patient autonomy, whereas CAM may be ethically questioned on grounds of inefficacy, safety and resource implications. Such ethical issues are likely to influence decisions on the inclusion/exclusion of CAM from medical syllabi.

The purpose of this study was to investigate the factors that influence the inclusion of CAM in undergraduate medical syllabi in the UK. A survey was used to measure, in a simple and brief way, the views of deans (or equivalent) of the country's medical schools. The goal was to provide answers to the following questions:

- To what extent is CAM being integrated into the education of future doctors?

- What factors influence decisions regarding the inclusion of CAM in medical curricula?

- To what extent may the inclusion of CAM represent an ethical problem?

\section{METHODOLOGY}

Individual emails were sent to the deans of the $31 \mathrm{UK}$ medical schools providing undergraduate medical degrees (see supplementary appendix 1 for a full transcript of the email).

The email sent to deans comprised an explanatory tract followed by specific questions, together with an attachment containing further information (see supplementary appendix 2 for a full transcript of the attachment).

The information provided was effectively a précis of the Introduction section of this article. There were six questions, as follows:

1. Does your syllabus presently contain any taught or practice components relating to the subject and methods commonly termed 'complementary and alternative medicine' (CAM)? 
2. If your syllabus has no CAM components, has the subject been discussed amongst your staff?

3. Are you aware of any requests, pressures or requirements from others (such as students, practitioners, the GMC, etc) to incorporate CAM into the syllabus?

4. Do you have any plans to amend your syllabus in respect of CAM components?

5. Do you consider that your staff would generally be in favour of or opposed to an increased prominence of CAM in medical education?

6. Do you personally consider the matter to be a problem?

The email stated:

\begin{abstract}
Answers will be collated, evaluated and the results submitted for publication in a peer reviewed academic journal. I hope that this will result in the issue gaining more attention, and possibly helping to inform future syllabus design. All answers will be treated in the strictest confidence. Answers will not be identified by institution name or interviewee name.
\end{abstract}

Emails were sent out in August 2009. Reminder emails were subsequently sent to all non-respondents. Some respondents replied stating that an alternative member of faculty should be contacted, and in some cases there was a degree of communication involved in reaching the most appropriate academics. Answers to the six questions were received between the date of the initial emails and April 2010.

Data from the responses were collated and are summarised in the following section. Because of the qualitative nature of the research approach, statistical analysis of the numerically presented results would have been inappropriate and has therefore not been conducted.

\section{ANALYSIS}

Response rate

Of 31 medical schools contacted, 18 responded to the survey. Thus, the overall response rate was $58.1 \%$. Several respondents attached course material to their replies.

\section{Responses to the individual questions}

Question 1

Does your syllabus presently contain any taught or practice components relating to the subject and methods commonly termed 'complementary and alternative medicine' (CAM)?

All 18 respondents gave an affirmative answer. Several of the respondents $(12 ; 66.7 \%)$ provided further commentary. CAM was most frequently studied as a student selected component (SSC), with eight of the $12(67.7 \%)$ comments indicating that SSCs in CAM were used. For example, one respondent wrote: "Homeopathy, acupuncture and herbal medicine are also available for study in depth as special study modules (SSCs)" (table 1, comment 50). Additionally, CAM was identified as being an area for student-directed learning within problem-based learning (PBL) programmes (2; 16.7\%), as "learning outcomes in a number of modules" (table 1 , note 50) and "Within the PBL cases there are incidents of patients taking or requesting CAM treatments" (table 1, comment 53).

Six $(33.3 \%)$ of the responses indicated that CAM was taught formally. The extent of this provision ranged from a single lecture to CAM being considered "several times along our spiral curriculum", including plenaries, tutorials, SSCs and presentations (table 1, comment 7). An extended session was employed by two $(16.7 \%)$ responding schools, as indicated by the following comments: "CAM lecture... followed by a session where (the students) meet a CAM practitioner with one of theirpatients" (table 1, comment 41); and "One day of teaching and experience in CAM" (table 1, comment 11).

CAM was considered as part of the 'community' component according to three (25\%) of the responses. Of these, two (16.7\%) stated their programmes offered community placements with CAM practitioners. Two $(16.7 \%)$ of the respondents indicated that CAM was mentioned where considered relevant. Areas where CAM teaching was deemed to be of relevance included clinical oncology, drug interactions and pain. Finally, it is noteworthy that one of the respondents included the following statement: "We have a senior lecturer of homeopathy on faculty staff" (table 1 , comment 50).

\section{Question 2}

If your syllabus has no CAM components, has the subject been discussed amongst your staff?

The fact that all of the responding medical schools indicated that their syllabus did include CAM components essentially rendered this question redundant. Nevertheless, two comments were received in response to this question. One comment simply stated that Tomorrow's Doctors required the inclusion of CAM. The other comment read:

Complementary medicine has been discussed amongst the curriculum planners of the MBCHB programme (in *** medical school) and we felt that it had a very limited place in our course. We are keen to emphasise that patients may choose to be supported by complementary medicine approaches but we are very keen to stress the practice of evidence based medicine. (table 1, comment 2)

\section{Question 3}

Are you aware of any requests, pressures or requirements from others (such as students, practitioners, the GMC, etc) to incorporate CAM into the syllabus?

The Yes/No answers were as follows: Yes=7 (38.9\%); $\mathrm{No}=3$ (16.7\%); eight (44.4\%) did not explicitly answer Yes or No but instead provided comments. A total of 15 comments were provided. Of the 18 responses, 14 $(77.8 \%)$ were affirmative and four $(22.2 \%)$ negative.

Of the respondents who commented in the affirmative, $10(71.4 \%)$ referred to GMC requirements. Of these, three $(21.4 \%)$ specifically mentioned Tomorrow's Doctors as a driver for inclusion, indicating that they were referring to the latest (2009) edition of this set of requirements (due for application from 2011/12 onwards). 
Table 1 Summary of responses

\begin{tabular}{|c|c|c|c|c|c|c|c|c|c|c|c|c|}
\hline \multirow[b]{2}{*}{ A } & \multicolumn{2}{|c|}{ Question 1} & \multicolumn{2}{|c|}{ Question 2} & \multicolumn{2}{|c|}{ Question 3} & \multicolumn{2}{|c|}{ Question 4} & \multicolumn{2}{|c|}{ Question 5} & \multicolumn{2}{|c|}{ Question 6} \\
\hline & $Y$ & 1 & $Y$ & 2 & $\mathrm{~N}$ & 3 & $\mathrm{~N}$ & 4 & $\mathrm{C}$ & 5 & $\mathrm{~N}$ & 6 \\
\hline$B$ & C & 7 & $\mathrm{~N} / \mathrm{A}$ & & C & 8 & C & 9 & C & 10 & $\mathrm{~N}$ & \\
\hline C & $Y$ & 11 & N/A & & $\mathrm{C}$ & 12 & $\mathrm{~N}$ & & $\mathrm{~N}$ & & $\mathrm{~N}$ & \\
\hline $\mathrm{D}$ & $Y$ & & N/A & & $Y$ & 13 & $\mathrm{~N}$ & & C & 14 & C & 15 \\
\hline$E$ & $\mathrm{Y}$ & 16 & & & C & 17 & $\mathrm{~N}$ & 18 & C & 19 & $\mathrm{~N}$ & 20 \\
\hline$F$ & $Y$ & & & & $Y$ & & $\mathrm{~N}$ & & $\mathrm{C}$ & 21 & $\mathrm{~N}$ & \\
\hline $\mathrm{G}$ & $Y$ & & N/A & & $Y$ & 22 & $\mathrm{~N}$ & & C & 23 & $\mathrm{~N}$ & \\
\hline $\mathrm{H}$ & $\mathrm{C}$ & 24 & C & 25 & C & 26 & $\mathrm{C}$ & 27 & C & 28 & $\mathrm{~N}$ & 29 \\
\hline I & $Y$ & 30 & N/A & & $Y$ & 31 & $\mathrm{C}$ & 32 & $\mathrm{C}$ & 33 & $\mathrm{C}$ & 34 \\
\hline J & $Y$ & & N/A & & $\mathrm{N}$ & & C & 35 & $\mathrm{C}$ & 36 & $\mathrm{~N}$ & \\
\hline K & $Y$ & & N/A & & $\mathrm{N}$ & & $\mathrm{N}$ & & C & 37 & $\mathrm{~N}$ & \\
\hline $\mathrm{L}$ & $\mathrm{C}$ & 38 & & & C & 39 & $\mathrm{~N}$ & & C & 40 & $\mathrm{~N}$ & \\
\hline$M$ & $Y$ & 41 & N/A & & C & 42 & C & 43 & C & 44 & C & 45 \\
\hline $\mathrm{N}$ & $Y$ & & N/A & 46 & C & 47 & $\mathrm{~N}$ & 48 & C & 49 & $\mathrm{~N}$ & \\
\hline 0 & $Y$ & 50 & N/A & & $Y$ & 51 & $\mathrm{~N}$ & & C & 52 & $\mathrm{~N}$ & \\
\hline$P$ & $\mathrm{C}$ & 53 & N/A & & C & 54 & C & 55 & C & 56 & C & 57 \\
\hline $\mathrm{Q}$ & $Y$ & 58 & N/A & & $Y$ & 59 & $Y$ & 60 & C & 61 & $\mathrm{~N}$ & \\
\hline $\mathrm{R}$ & $Y$ & 62 & N/A & & $Y$ & 63 & $\mathrm{~N}$ & & $\mathrm{C}$ & 64 & $\mathrm{~N}$ & \\
\hline
\end{tabular}

Comments

1.

Our curriculum includes a few occasions when complementary medicine is discussed. This occurs particularly in relation to a clinical oncology attachment that students undertake in the penultimate year of the course. Students also have an opportunity, should they wish, to choose to write about some aspects of complementary medicine, although very few students take up this option.

2. Complementary medicine has been discussed among the curriculum planners of the MBCHB programme (in *** medical school) and we felt that it had a very limited place in our course. We are keen to emphasise that patients may choose to be supported by complementary medicine approaches, but we are very keen to stress the practice of evidence based medicine.

3. We are not aware of any requests, pressures or requirements from any groups of individuals or statutory bodies to include complementary medicine in our curriculum.

4. We have no plans to amend our curriculum with respect to complementary medicine at present.

5. I do not think that staff would be in favour of an increased prominence of complementary medicine within medical education as they are all very keen to support evidence based teaching and practice. However, we are keen to ensure that students understand that patients may wish to choose such a clinical pathway.

6. In answer to your final question as to whether or not we consider the matter to be a problem, I am a little uncertain as to what the question is getting at. We believe that we have the balance of complementary medicine teaching and information right within our curriculum and have no plans to change it.

7. Students encounter CAM several times along our spiral curriculum, Their first encounter is early in year 1 with a trigger being present in a PBL case, this trigger is supported with a plenary entitled 'Complementary and alternative medicine' and a Pharma-CAL-ogy tutorial on alternative therapies. The topic is revisited again in year 2 within a PBL case and then CAM is considered throughout all the year 3 and 4 pathway weeks. In year 5 it is embedded within a number of indicative presentations.

8. I believe we were asked about the level of CAM in our syllabus by the GMC relatively recently

9. None at present, we do however systematically review our content and if there were enough evidence to suggest we needed greater coverage, efforts would be made to 'fill the perceived gap'.

10. I suspect as with any change in curriculum, their position would depend on the rationale and evidence for such an increase.

11. During our 4th year (equivalent to 3rd year in most university medical courses) all students have one day of teaching and experience in CAM. The aim of this day is to introduce CAM to all the students so that they get an opportunity to hear about how patients use CAM in dealing with health problems. They get some idea of who does what and why and when it can be beneficial. I have attached the timetable from last autumn. There may also be opportunities for students to pursue a 4 week SSM into an aspect of CAM later in the same clinical year.

12. Our current level of inclusion seems to meet needs.

13. CAM included formally following request from GMC in 2001 . No outstanding requests following curriculum revision in 2005.

14. Opposed.

15. Medical students need to be aware of CAM and the types of therapies patients might be taking.

16. The curriculum contains both taught components (within a fully integrated curriculum) and practice components-during clinical attachments in relation to pain management and palliative care, and general practice. "Tomorrow's Doctors 2", from GMC, included CAM as a theme. 
18. Not at present.

19. Some staff would be in favour and others would be opposed to an increased prominence of CAM in the curriculum.

20. Not currently.

21. Opposed.

22. GMC.

23. Varies. I think all staff appreciate that some understanding of CAM is important as so may people/patients use it.

24. In 2008/09 the school was inspected by the GMC Education Committee (QABME). In their draft report they say that they were satisfied that "students were aware of alternative and complementary therapies and learn about them in Year 2, and a student-selected component is available". Also some community placements in Year 2 (referred to as 'Medicine in Society') are with CAM practitioners only a small minority of students are exposed to them though. The exposure to CAM in the 'core' curriculum in Year 2 is minimal, in my view just one lecture-workshop by a professor of CAM from the University of ${ }^{* * *}$.

25. Surely it is unlikely that any MBBS curriculum in the UK makes no reference to CAM? $\sim$ it is a requirement under Tomorrow's Doctors 2003.

26. The implication of your $Q$ is that CAM is under-represented (or not at all) in the MBBS curriculum $\sim$ not really applicable in our case. Numerous medical students here are strongly in favour of CAM and would no doubt like greater coverage. However there are also students who are adamantly opposed, and would like the school to reduce its coverage (eg, by dropping certain community placements in Y2). The GMC is satisfied with the current treatment of CAM in our MBBS curriculum (see Q1).

27. I shall be making a proposal to introduce a new module with elements interspersed throughout the MBBS curriculum. The module would have 8 major topics, of which CAM would be one.

28. Academic staff at ${ }^{* * *}$ hold views on CAM that span the spectrum from strongly opposed to favourable. Special criticism has been directed here at the dubious scientific basis for homeopathy. One expects inevitable resistance when existing curricular content has to make way for new elements, particularly if those have an uncertain evidence base.

29. I personally feel that our school's existing MBBS provision on CAM is too little, but any curricular element has to justify its inclusion.

30. We have a lecture on complementary medicine as part of our introductory clinical pharmacology course.

31. The GMC Tomorrow's Doctors outcome of "Demonstrating awareness that many patients use complementary and alternative therapies" etc is the statement against which we are judged, so that is the main driver. Students are certainly interested in complementary medicine and we used to have an SSC run by enthusiasts which was popular, but that did not prove sustainable. There is no great clamour for increased coverage.

32. We are in the midst of a curriculum review, so the location of teaching may change, but it is unlikely that the coverage will be much different in extent.

33. Not really.

34. Not when considered in the context of all the other outcomes in Tomorrow's Doctors that have to be addressed in 5 years!

35. We are currently undertaking a curriculum review and CAM will be considered together with every other element that is covered in the 4 year programme to determine when, if and how the learning and teaching on this subject will be covered.

36. I do not have sufficient insight into the thoughts of the totality of our faculty to be able to answer this question honestly. It is likely that I will be better informed during the curriculum review process.

37. Subjective response likely to reflect my attitudes. Not in favour of increasing from present level. The answer is not evidence (robust) based, but I think current staff would think level of content is not in need of change.

38. A couple of lectures that cover patient-centred treatment, which explicitly review a range of CAM therapies and their perceived value. Also CAM issues are raised in the core teaching where relevant-for example acupuncture in the context of the physiology of pain, herbal remedies especially in the context of drug interactions, but also where they have known mechanisms of action. Other than that, there are student selected components for those who are interested.

39. The GMC mentions teaching about CAM in Tomorrow's Doctors ("Graduates must be aware of the existence and range of such therapies, why some patients use them, and how these might affect other types of treatment that patients are receiving"), so this is a requirement.

40. No one to my knowledge has objected to the GMC requirement above, which encompasses the psychological benefits of alternative approaches and how this can assist conventional therapy. Beyond that, I think that if an alternative therapy had an evidence base on a par with conventional medicine then staff would be happy to devote a proportionate amount of time to it, but not to CAM that lack evidence. We have far too little time to teach the basis for conventional, proven medicines.

41. In the core curriculum there is a session in Year 1 where the students have a lecture on CAM (lecture notes attached) and this is followed by a session where they meet a CAM practitioner with one of their patients. The lesson plan for this session is also attached. Additionally we have various SSC options including SSCs in CAM (in general) and homeopathy (intro document for same attached).

42. Not really. ${ }^{* * *}$ has a lot of CAM practitioners - certainly in the central area and so it is something students are aware of. I don't think CAM teaching is a requirement of the TD3. CAM teaching is not particularly in demand from students. 
43. We think we have got it about right at present. I would like to see perhaps another teaching session on CAM later in the curriculum perhaps in years 3-5. Their current teaching in Year 1 comes a bit early.

44. I think that would vary from person to person. In fields like rheumatology many, perhaps the majority of patients, use or have used some form of CAM, so the case for it there is strong. I think that the answer to that question also depends on the quality of the teaching. We follow a reasonably/sufficiently evidence-based approach-for instance we held a public debate between a homeopathic researcher and an epidemiology professor.

45. I personally, as a consultant senior lecturer, think that there are issues about CAM education that need to be addressed in the curriculum.

46. However we did discuss and used a Delphi technique to decide on content etc.

47. GMC requirements.

48. We monitor and quality assure the current CAM content.

49. They accept the current level we have in the curriculum-any more would be very difficult due the need for other subjects in current curriculum.

50. Yes, ours is a PBL centred course, and complementary medicine is flagged as a learning objective in a number of modules. Homeopathy, acupuncture and herbal medicine are also available for study in depth as special study modules (SSCs). We have a senior lecturer of homeopathy on faculty staff.

51. The original decision was influenced by the GMC, and also by pharmacologists who wanted students to be aware that patients used CAM.

52. This depends on which staff you consult!

53. We have a PBL based curriculum. Within the PBL cases there are incidents of patients taking or requesting CAM treatments. We support this with a number of seminars and lectures. The aim is to give the students an awareness of CAM rather than detailed knowledge. Some students choose to look at CAM as part of their student selected studies.

54. The GMC requires an awareness of CAM but does not require detailed knowledge or the ability to prescribe CAM.

55. The curriculum is constantly under review but we do not at present have specific plans to amend the CAM component.

56. We are in favour of educating the students about CAM but do not see that increased time or effort directed towards CAM would be appropriate given the other important areas within the curriculum which need to be given increased attention such as substance mis-use and prescribing.

57. As above.

58. In Years 2 and 4.

59. As it is common question from patients, we think it is important for students to be aware of.

60. Dr ${ }^{* * *}$, consultant oncologist is looking at this currently.

61. Would need to be reviewed to ensure balance is correct, may be some resistance.

62. Yes, taught within the community part of the programme.

63. GMC.

64. Possibly in favour.

The 18 responding medical schools have been randomly designated as $A-R$ in the table. Answers for each question (where a response was given) are indicated by $\mathrm{Y}$ for 'Yes', $\mathrm{N}$ for 'No', and N/A for 'Not Applicable'. Where no explicit 'Yes/No' response was given but a comment was provided instead, this is indicated by $\mathrm{C}$. The numbers in the body of the table refer to comments, which are set out below the table. All identifying features of specific medical schools or individuals have been removed.

CAM, complementary and alternative medicine; GMC, General Medical Council; PBL, problem-based learning; SSC, student selected component; SSM, special study module; TD3, Tomorrow's Doctors 2003.

Three respondents indicated that the GMC had taken a view regarding CAM provision in their specific medical school programme. Statements in this regard were: "CAM included formally following request from GMC in 2001" (table 1, comment 13); "I believe we were asked about the level of CAM in our syllabus by the GMC relatively recently" (table 1 , comment 8 ); and "The GMC is satisfied with the current treatment of CAM in our MBBS curriculum" (table 1, comment 26).

Of the clearly negative responses, one respondent commented that Tomorrow's Doctors did not stipulate that CAM be included. Another stated: "We are not aware of any requests, pressures or requirements from any groups of individuals or statutory bodies to include complementary medicine in our curriculum" (table 1, comment 3).

Several comments referred to student demands, or the lack thereof, for CAM provision. Here, the picture is mixed, as exemplified by the following comments (from three separate respondents): "Students are certainly interested in complementary medicine... (however) there is no great clamour for increased coverage" (table 1, comment 31); "Numerous medical students here are strongly in favour of CAM and would no doubt like greater coverage. However there are also students who are adamantly opposed, and would like the school to reduce its coverage" (table 1, comment 26); and "CAM teaching is not particularly in demand from students" (table 1, comment 42).

Other than the requirements of the GMC or student demands, one additional reason for including CAM was given, namely a perceived need to make students aware of CAM in light of the fact that it was often asked for by patients.

\section{Question 4}

Do you have any plans to amend your syllabus in respect of CAM components? 
The Yes/No answers were as follows: Yes $=1(5.6 \%)$; $\mathrm{No}=11(61.1 \%)$; six $(33.3 \%)$ did not indicate Yes or No but instead provided comments. A total of 10 comments were provided. Of the 18 responses, only one $(5.6 \%)$ was clearly affirmative. Six of the respondents gave a 'not at present' answer; combining these 'not at present' answers with the straightforward 'no' answers gives 14 $(77.8 \%)$ with no plans to amend their syllabi. The remaining three respondents indicated that their curricula were presently under review, and may change in respect to CAM coverage as a consequence; however one of these respondents stated that it was unlikely that the extent of coverage would change much.

\section{Question 5}

Do you consider that your staff would generally be in favour of or opposed to an increased prominence of CAM in medical education?

Several comments, often quite extensive in nature, were received for this question, although a minority of respondents gave short simple answers such as 'no', 'opposed', or 'not really'. Of all the comments, only one $(5.6 \%)$ came close to giving a positive answer ("possibly in favour"). The remaining $17(94.4 \%)$ respondents were either equivocal or negative in their responses.

Seven $(38.9 \%)$ respondents indicated that they considered their staff would generally be opposed to an increased prominence of CAM. Another seven (38.9\%) considered that there was a spectrum of views among their colleagues, and therefore that generalisation was not possible (or that they did not know the views of their colleagues sufficiently well to form a general view). A further two $(11.1 \%)$ respondents simply indicated that there was no space within their syllabi to include further CAM coverage. One respondent stated: "I suspect as with any change in curriculum, their position would depend on the rationale and evidence for such an increase" (table 1, comment 10).

Some of the comments provide interesting insights. One comment suggests that the field of practice is a potential factor in forming the opinion of staff: "I think that would vary from person to person. In fields like rheumatology many, perhaps the majority of patients, use or have used some form of CAM, so the case for it there is strong" (table 1, comment 44).

The nature of the pedagogy was cited as a potential factor: "I think that the answer to that question also depends on the quality of the teaching. We follow a reasonably/sufficiently evidence-based approach-for instance we held a public debate between a homeopathic researcher and an epidemiology professor" (table 1, comment 44).

Two respondents $(38.9 \%)$ considered that the type of CAM was of importance, with certain forms of CAM being more problematic than others in terms of their likely acceptance into curricula. Their comments were:

Academic staff at (this medical school) hold views on CAM that span the spectrum from strongly opposed to favourable. Special criticism has been directed here at the dubious scientific basis for homeopathy. One expects inevitable resistance when existing curricular content has to make way for new elements, particularly if those have an uncertain evidence base. (table 1, comment 28)

And:

No one to my knowledge has objected to the GMC requirement above, which encompasses the psychological benefits of alternative approaches and how this can assist conventional therapy. Beyond that, I think that if an alternative therapy had an evidence base on a par with conventional medicine then staff would be happy to devote a proportionate amount of time to it, but not to CAM that lack evidence. (table 1, comment 40)

\section{Question 6}

Do you personally consider the matter to be a problem?

Interestingly, no respondents provided an affirmative answer to this question. The closest response to a positive answer was provided by one respondent $(5.6 \%)$ who gave a 'no' response but then went on to comment: "I personally feel that our school's existing provision on CAM is too little, but any curricular element has to justify its inclusion" (table 1, comment 29).

A few additional comments were provided, which generally expressed the view that students ought to be given some education in CAM.

\section{DISCUSSION}

The foregoing data appear to indicate that CAM education is widespread in undergraduate medical curricula throughout the UK. This finding must to some extent be treated with caution however, since only approximately $58 \%$ of the UK's medical schools responded to the survey. It is not possible to say whether systematic reasons lay behind the non-responses, such as a lack of interest in CAM or a lack of CAM provision in the medical schools concerned. The following discussion points apply specifically to the (approximately) threefifths of medical schools that did respond. The extent to which these points may be generalised to all UK medical schools cannot be determined from the available data.

The survey data demonstrate that medical schools appear to be meeting the requirements of the GMC's Tomorrow's Doctors for CAM education. However, the extent to which individual syllabi incorporate CAM varies widely, ranging from minimal coverage (one CAM lecture in the entire course) to substantially more extensive provision (CAM considered throughout the course, employing a range of teaching and learning approaches). The majority of responding schools do not envisage changing their coverage of CAM, at least in the short term.

It is clear from the survey responses that inclusion of CAM in undergraduate medical curricula has been driven in large part by GMC requirements. However, although all responding schools indicated that CAM was covered in their syllabi, the fact that two of the schools 
considered that there were no formal requirements suggests that, at least at the time of surveying, not all schools were up-to-date in terms of Tomorrow's Doctors.

Broad disparities in CAM education may be taken to indicate a healthy diversity of provision, reflective of a welcome educational freedom enjoyed by individual medical schools. This viewpoint is supported by the fact that, despite the widely varying range of provision, respondents did not consider the extent of provision of CAM within their own curriculum to be a problem. This suggests that a consensus has been reached within each medical school, which would seem to fit well with the notion of giving schools freedom to decide how they deal with CAM in the curriculum. However, it can also be argued that the range of provision is so markedly wide as to be problematic: if CAM education is important (as implied by the GMC), then minimal standards of provision perhaps ought to be specified. In this respect, it is notable that Tomorrow's Doctors only devotes a single sentence to the issue of CAM education (as quoted in the introduction to the present paper). It would perhaps be useful for the GMC to be more specific in this context, while avoiding being unduly prescriptive.

Beyond GMC requirements, the perceived preferences of medical students appear to be an important influence on the extent to which CAM may be incorporated into curricula. Here the views of students seem to be pulling in opposite directions: some students are 'strongly in favour' of increased coverage, while others are 'adamantly opposed'. Other students are reported as being neutral on the issue. Similarly, among faculty members, a degree of polarisation was also reported. It is perhaps unsurprising that strong, disparate views are held about CAM among medical students and educators. The scientifically questionable nature of CAM, combined with its paradoxical popularity among many patients and some medical professionals, renders it an area of substantial contention.

Support for CAM education (among students and staff) could simply be reflective of a wish to understand what patients may be exposed to; alternatively, such support could indicate an ideological favouring of, or belief in, the utility of CAM. It is evident from the survey results that both of these contrasting motivations are present within medical schools, although the relative extent to which each plays a part in determining CAM inclusion cannot be discerned from the available data.

There is a fundamental difference between (a) critically describing CAM approaches and (b) advocating CAM in a non-analytical fashion. The former is probably of unquestionable benefit to doctors, and support for this form of CAM education is evident from many of the survey responses. By contrast, educating and training medical students in CAM techniques would be highly contentious. It is thus reassuring to observe from the survey results that CAM education appears to be predominantly of variety (a).

Nevertheless, potentially problematic approaches to CAM are evident in a minority of the survey responses.
First, CAM is in some cases reported as being taught by CAM practitioners or CAM-specific academics. It is difficult to conceive of education from such sources as being anything other than training students to appreciate and apply CAM in practice. This is arguably a form of indoctrination, and is thus of significant ethical concern.

Another potentially problematic approach is the widespread use of student-centred assignments as a form of CAM education. Many pro-CAM journals, books and websites exist, and it would be of concern if relatively inexperienced students were assimilating such information in an uncritical fashion in the context of coursework preparation. It should be emphasised that these are potential problems: more research is needed to determine the extent to which such problems actually pertain to current syllabi.

A counter-argument to the above concerns may be posited, to the effect that exposure to CAM staff and literature enriches the teaching and experiences of medical students, who are otherwise mainly exposed to a narrow range of teachers, for example clinical staff. Optimistically, critical thinking among students may be enhanced by such an approach.

\section{CONCLUDING REMARKS}

Inevitably, most practicing doctors will be asked about CAM by some of their patients, and all will have patients who use forms of CAM. It is therefore important that medical students are made aware of CAM. This survey observed a wide variability between medical schools in terms of their approaches to CAM education. Accordingly, the GMC may wish to clarify its requirements for CAM inclusion within the undergraduate medical syllabus.

\section{LIMITATIONS AND FUTURE WORK}

This study involved all UK undergraduate medical schools and had a reasonable overall response rate considering the context. However, it is possible that the views of deans of the approximately two-fifths of schools that did not respond, if known, might alter the results. There are no strong a priori reasons to suppose that systematic bias would likely undermine the fundamental

Table 2 Analysis of responding versus non-responding medical schools: problem-based learning (PBL) courses*

\begin{tabular}{lccc} 
& Responding & $\begin{array}{l}\text { Non- } \\
\text { responding }\end{array}$ & Total \\
\hline PBL & 4 & 2 & 6 \\
Non-PBL & 14 & 11 & 25 \\
Total & 18 & 13 & 31 \\
Fisher's exact test & & & \\
$\quad$ Left: $p=0.824$ & & & \\
Right: $p=0.501$ & & & \\
2-tail: $p=1$ & &
\end{tabular}

${ }^{*} \mathrm{PBL}$ elements are contained in many undergraduate medical courses, to a varying extent. The PBL courses referred to above are those in which PBL is the core form of pedagogy. 
Table 3 Analysis of responding versus non-responding medical schools: accelerated graduate stream*

\begin{tabular}{lccc}
\hline & Responding & $\begin{array}{l}\text { Non- } \\
\text { responding }\end{array}$ & Total \\
\hline Graduate stream & 9 & 7 & 16 \\
No graduate stream & 9 & 6 & 15 \\
Total & 18 & 13 & 31 \\
Fisher's exact test & & \\
$\quad$ Left: $p=0.561$ & & \\
$\quad$ Right: $p=0.717$ & & \\
2-tail: $p=1$ & \\
*Many medical schools permit graduate entry; however this table \\
restricts the term 'graduate stream' to courses in which graduates \\
gain advanced entry and study for at least 1 year less than non- \\
graduate entrants.
\end{tabular}

conclusions, expressed above, as to the extent of CAM coverage and the ways in which it has been treated in terms of curriculum design. Given that it was deans who were surveyed (a strength of this study), non-responses may perhaps be attributable simply to the status and concomitant workloads of those concerned. However, missing data due to non-responding subjects always gives prima facie concern as to whether bias may be present. ${ }^{32}$ Thus, a number of analyses were conducted to explore whether any systematic differences between responders and non-responders could be discerned.

Several important characteristics that could conceivably serve as potential sources of bias were considered. These were: teaching mode employed (PBL vs traditional); whether an accelerated graduate entry route was offered; the geographical location of the medical school; the era in which the school opened; and the size of the student intake. The sex of the dean was also considered, as a personal characteristic from which response bias might potentially arise. An attempt was also made to address two additional characteristics: (a) physical location (campus vs urban settings) and (b) whether linked hospitals offered CAM services. However, problems of definition and lack of available data precluded a quantitative appraisal of these two attributes.

The resulting data analyses are shown in tables $2-8$. In no case is there evidence of a correlation between

Table 4 Analysis of responding versus non-responding medical schools: location*

\begin{tabular}{lccc}
\hline & Responding & $\begin{array}{l}\text { Non- } \\
\text { responding }\end{array}$ & Total \\
\hline North & 9 & 8 & 17 \\
South & 9 & 5 & 14 \\
Total & 18 & 13 & 31 \\
Fisher's exact test & & \\
$\quad$ Left: $\mathrm{p}=0.394$ & & \\
$\quad$ Right: $\mathrm{p}=0.842$ & & \\
2-tail: $\mathrm{p}=0.717$ & & \\
*The category 'North' includes Scotland, Northern Ireland, and the \\
following regions of England: Midlands, North East and North West. \\
The category 'South' includes London, Wales and the following \\
regions of England: East Anglia, South and South West.
\end{tabular}

Table 5 Analysis of responding versus non-responding medical schools: era of opening ${ }^{*}$

\begin{tabular}{lccc}
\hline & Responding & $\begin{array}{l}\text { Non- } \\
\text { responding }\end{array}$ & Total \\
\hline Post-1960 & 6 & 4 & 10 \\
Pre-1960 & 12 & 9 & 21 \\
Total & 18 & 13 & 31 \\
Fisher's exact test & & \\
$\quad$ Left: $p=0.703$ & & \\
$\quad$ Right: $p=0.597$ & & \\
2-tail: $p=1$ & \\
*The data were categorised into the eras shown because specific \\
dates of opening are problematic for the following reasons: (a) the \\
history of several medical schools has been one of mergers and \\
name changes, making definitive dates of establishment unreliable; \\
and (b) such data are not suitable for statistical analysis.
\end{tabular}

a characteristic and a tendency to respond or not respond. This is evident from simple inspection of the tabulated data, and confirmed by the fact that all $\mathrm{p}$ values are greater than 0.05 (ie, the observed differences are not statistically significant).

However, these results show only that bias does not exist for the characteristics selected: they do not guarantee freedom from bias. It remains possible that other unexamined characteristics could be sources of bias. However, it is beyond the scope of the present paper to attempt to analyse each and every conceivable characteristic in order to attempt to eliminate this possibility. Therefore, as expressed at the beginning of the Discussion section (above), the findings of this study apply specifically only to the (approximately) three-fifths of medical schools that did respond. This study may be categorised as one in which the residual possibility of bias does not remove the impact of the findings. ${ }^{33}$ The various responses obtained in this study provide potentially useful information on the range of ways in which (at least some) UK medical schools deal with CAM.

Due to the brief and simple form of survey used, it is not possible from the resultant data to distinguish between the different types of CAM involved. This is an

Table 6 Analysis of responding versus non-responding medical schools: size, by first year intake-grouped data*

\begin{tabular}{llll}
\hline & Responding & $\begin{array}{l}\text { Non- } \\
\text { responding }\end{array}$ & Total \\
\hline Under 222 & 12 & 5 & 17 \\
Above 222 & 6 & 8 & 14 \\
Total & 18 & 13 & 31 \\
Fisher's exact test & & & \\
$\quad$ Left: $p=0.973$ & & & \\
$\quad$ Right: $p=0.117$ & & & \\
2-tail: $p=0.157$ & & & \\
\hline
\end{tabular}

*The data included are for home and EU students only; overseas student numbers (typically about $10 \%$ more) are not included. The figure of 222 was selected as the grouping criterion because it is the mean value. The range (top and bottom values) is not shown, as doing so would compromise confidentiality. Data were obtained from medical school websites; where such data were not available online, admissions offices were contacted by email or telephone. 
Table 7 Analysis of responding versus non-responding medical schools: size, by first year intake-continuous data*

\begin{tabular}{lll}
\hline & Responding & $\begin{array}{l}\text { Non- } \\
\text { responding }\end{array}$ \\
\hline Mean & 199.6 & 253.4 \\
SD & 60.8 & 91.1 \\
SE & 14.3 & 25.6 \\
t Test (2-tail, unpaired) & & \\
\multicolumn{1}{c}{$\mathrm{p}=0.079$} & & \\
\hline
\end{tabular}

*The range (top and bottom values) is not shown, as doing so would compromise confidentiality.

important limitation of the study. Despite their contentious nature in terms of a weak evidence base and inherent scientific implausibility, CAM therapies such as acupuncture and chiropractic are part of several National Institute for Health and Clinical Excellence guidelines and are commonly used alongside biomedical interventions, whereas other forms of CAM, such as faith healing or therapeutic touch, are interventions that lie outside the medical sphere. Any follow-up study should seek to discriminate between these different forms of CAM.

The wording of two of the questions is, in retrospect, somewhat problematic. In question 5 (Do you consider that your staff would generally be in favour of or opposed to an increased prominence of CAM in medical education?), the use of the wording 'increased prominence' is arguably a somewhat leading question and would have been better phrased as a 'change in' prominence or 'increased/decreased' prominence. In question 6 (Do you personally consider the matter to be a problem?), it is perhaps not clear as to what the matter' precisely refers to.

Future work is suggested by this study. Teaching and learning approaches should be examined further. Of particular importance would be elucidation of the ways in which CAM education is framed in respect of the dichotomy between approaches based on critical description versus those based on training or advocacy. In addition, it would be desirable to obtain further detailed information about the main teaching methods (eg, PBL, traditional, mixture of both), the types of medical schools (eg, new/old), together with a breakdown of medical students in terms of gender and ethnicity. Such factors

Table 8 Analysis of responding versus non-responding medical schools: sex of dean

\begin{tabular}{llll}
\hline & Responding & $\begin{array}{l}\text { Non- } \\
\text { responding }\end{array}$ & Total \\
\hline Male & 12 & 9 & 21 \\
Female & 6 & 4 & 10 \\
Total & 18 & 13 & 31 \\
Fisher's exact test & & & \\
$\quad$ Left: $p=0.597$ & & & \\
Right: $p=0.703$ & & & \\
2-tail: $p=1$ & & & \\
\hline
\end{tabular}

may be important variables that could plausibly influence decisions on how much CAM is taught in each school.

Follow-up research could be based initially on a further email survey. Ideally, semi-structured interviews would be conducted, and it would be potentially very interesting to conduct focus group-based research. As regards the possibility of conducting interviews, the present survey asked respondents whether they would be willing to participate in follow-up interviews: positive responses were elicited from most respondents.

Additional characteristics as potential sources of response bias

The above characteristics do not represent an exhaustive list. Additional possibilities can be envisaged, and two of these were preliminarily examined, as follows.

\section{Urban versus campus}

The physical nature of the university/medical school, in terms of whether it is campus-based or urban, might conceivably have a bearing as to whether a given medical school responded, perhaps through different cultures prevailing in the two types. However, the question is clouded by difficulties of definition: many originally urban universities have evolved into multi-location facilities, comprising several campus-like sites; and some urban universities locate their medical schools in these separate sites. Therefore, the distinction between campus-based and urban universities/medical schools is indistinct. Thus, it was not possible to effectively categorise the subjects of this study into these two (or any other distinct) groupings. It is however worth noting that there is some overlap between this category and the 'era of opening' category (table 5), because more of the post-1960 medical schools are closer to the 'campus' style than their pre-1960 counterparts. It is notable that no statistically significant difference in response rates was observed on the 'era of opening' category.

\section{Linked hospitals}

An interesting possibility is that the nature of the hospitals in which medical students train might influence response rates; specifically, the provision (or lack thereof) of CAM services might be important. Accordingly, an informal internet survey of the main hospitals linked to each medical school was conducted. This consisted simply of identifying the hospitals concerned (via medical schools' websites) and then looking at the services listed on each hospital's website.

Interestingly, a distinct absence of CAM-specific services was evident in the services listings of the great majority of the hospitals. This may plausibly be accounted for by two possibilities: (a) medical schools deliberately avoid hospitals that either provide CAM services (or are themselves CAMbased, eg, NHS homeopathic hospitals); or (b) CAM services within mainstream hospitals used for training are offered within major specialities (eg, pain management, palliative care) and therefore not listed as specific services. These possibilities (which are not mutually exclusive) are worthy of future research; substantive empirical work would be required in order to find answers. In respect of the present study, the lack of available data on this issue meant that it was not possible to determine whether the provision of CAM services by linked hospitals presented a source of response bias. 
Funding This work was funded by a grant from the Carnegie Trust for the Universities of Scotland. The author is independent from the funder, and study design, collection, analysis, and interpretation of data and the writing of the article and the decision to submit it for publication were not influenced by the funder.

Competing interests None.

Ethics approval The School of Contemporary Sciences Research Ethics Committee approved this work.

Provenance and peer review Not commissioned; externally peer reviewed

Data sharing statement Data will be shared, to the extent that anonymity and confidentiality are preserved.

\section{REFERENCES}

1. Traditional Medicine: Definitions. World Health Organisation (WHO), 2000. http://www.who.int/medicines/areas/traditional/definitions/en/ (accessed May 2011).

2. What Is Complementary and Alternative Medicine? National Center for Complementary and Alternative Medicine (NCCM), 2010. http:// nccam.nih.gov/health/whatiscam/ (accessed May 2011).

3. Sampson W, Atwood K. Propagation of the absurd: demarcation of the absurd revisited. Medical J Aust 2005;183:580-1.

4. Smith KR, Sampson W. Word use and semantics in alternative medicine: a survey of editors of medical and related journals. Medscape J Med 2008;10:125

5. Science and Technology-Sixth Report. House of Lords, 2000. http:// www.parliament.the-stationery-office.co.uk/pa/ld199900/ldselect/ Idsctech/123/12303.htm (accessed May 2011).

6. What is Complementary and Alternative Medicine (CAM)? NHS Evidence, 2011. http://www.library.nhs.uk/cam/page.aspx? pagename $=$ CAM (accessed May 2011).

7. Ernst $\mathrm{E}$, White $\mathrm{A}$. The BBC survey of complementary medicine use in the UK. Complement Ther Med 2000;8:32-6.

8. Bausell RB. Snake Oil Science. New York: Oxford University Press, 2007.

9. Ernst E. Prevalence of use of complementary/alternative medicine: a systematic review. Bull World Health Organ 2000;78:252-7.

10. Winnick TA. Medical doctors and complementary and alternative medicine: the context of holistic practice. Health 2006;10: $149-73$

11. Brokaw JJ, Tunnicliff G, Raess BU, et al. The teaching of complementary and alternative medicine in US medical schools: A survey of course directors. Acad Med 2002;77:876-81.

12. Colquhoun D. Science degrees without the science. Nature 2007:446:373-4

13. Lloyd LF, Simon B, Dunn LR, et al. The status of complementary and alternative medicine education in US physician assistant programs. Teach Learn Med 2007;19:174-9.
14. Nicolao M, Tauber MG, Marian F, et al. Complementary medicine courses in Swiss medical schools: actual status and students experiences. Swiss Med Wkly 2010;140:44-51.

15. Stratton TD, Benn RK, Lie DA, et al. Evaluating CAM education in health professions programs. Acad Med 2007;82:956-61.

16. Wetzel MS, Eisenberg DM, Kaptchuk TJ. Courses involving complementary and alternative medicine at US medical schools. JAMA 1998;280:784-7.

17. Anon. Tomorrow's Doctors. 2009. General Medical Council (GMC). http://www.gmc-uk.org/education/undergraduate/tomorrows_ doctors_2009.asp (accessed May 2011).

18. Votova K. Complementary and alternative medicine: ethics, the patient, and the physician. Can J Aging 2009;28:400-2.

19. Furlow ML, Patel DA, Sen A, et al. Physician and patient attitudes towards complementary and alternative medicine in obstetrics and gynecology. BMC Complement Altern Med 2008;8:35.

20. Sirois FM, Purc-Stephenson RJ. When one door closes, another door opens: physician availability and motivations to consult complementary and alternative medicine providers. Complement Ther Clin Pract 2008:14:228-36.

21. Nahin RL, Dahlhamer JM, Taylor BL, et al. Health behaviors and risk factors in those who use complementary and alternative medicine. BMC Public Health 2007;7:217.

22. Nathanson I, Sandler E, Ramirez-Garnica G, et al. Factors influencing complementary and alternative medicine use in a multisite pediatric oncology practice. J Pediatr Hematol Oncol 2007;29:705-8.

23. Cherrington A, Lewis $\mathrm{CE}, \mathrm{McCreath} \mathrm{HE}$, et al. Association of complementary and alternative medicine use, demographic factors, and perimenopausal symptoms in a multiethnic sample of women: the ENDOW study. Fam Community Health 2003;26:74-83.

24. Rosenberg El, Mechaber AJ, Calleson D, et al. Physician attitudes towards complementary and alternative chronic pain therapies. J Investig Med 2003;51:280.

25. Kramer N. Why I would not recommend complementary or alternative therapies: a physician's perspective. Rheum Dis Clin North Am 1999;25:833-43.

26. Kemper KJ, O'Connor KG. Pediatricians' recommendations for complementary and alternative medical (CAM) therapies. Ambul Pediatr 2004;4:482-7.

27. Smith KR. Anomalous therapies and public health: a utilitarian bioethical response. Public Health Nurs 2008;25:269-77.

28. Ernst E. Advice offered by practitioners of complementary/alternative medicine: an important ethical issue. Eval Health Prof 2009;32:335-42.

29. Jacobson GM, Cain JM. Ethical issues related to patient use of complementary and alternative medicine. $J$ Oncol Pract 2009;5:124-6.

30. Ernst E, Cohen $\mathrm{MH}$, Stone J. Ethical problems arising in evidence based complementary and alternative medicine. $J$ Med Ethics 2004;30:156-9.

31. Ernst E. Ethics and complementary and alternative medicine. Ann Intern Med 2003;138:940.

32. Altman DG, Bland JM. Missing data BMJ 2007:334:424.

33. Evans SJW. Good surveys guide. BMJ. 1991;302:302-3. 